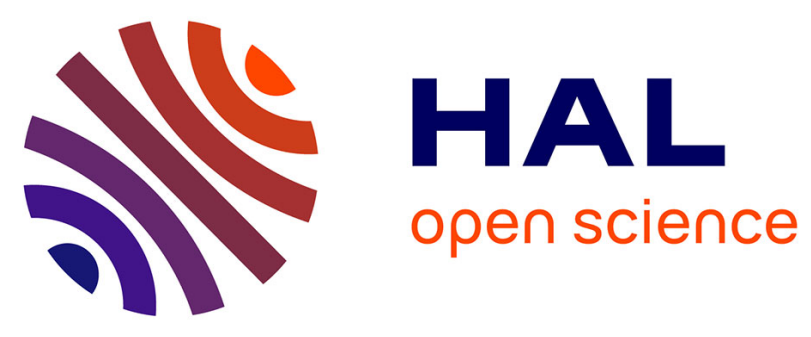

\title{
Levels of angiogenic factors in patients with multiple myeloma correlate with treatment response
}

Ludek Pour, Hana Svachova, Zdenek Adam, Martina Almasi, Lucie Buresova, Tomas Buchler, Lucie Kovarova, Pavel Nemec, Miroslav Penka, Jiri Vorlicek, et al.

\section{To cite this version:}

Ludek Pour, Hana Svachova, Zdenek Adam, Martina Almasi, Lucie Buresova, et al.. Levels of angiogenic factors in patients with multiple myeloma correlate with treatment response. Annals of Hematology, 2009, 89 (4), pp.385-389. 10.1007/s00277-009-0834-3 . hal-00535095

\section{HAL Id: hal-00535095 https://hal.science/hal-00535095}

Submitted on 11 Nov 2010

HAL is a multi-disciplinary open access archive for the deposit and dissemination of scientific research documents, whether they are published or not. The documents may come from teaching and research institutions in France or abroad, or from public or private research centers.
L'archive ouverte pluridisciplinaire HAL, est destinée au dépôt et à la diffusion de documents scientifiques de niveau recherche, publiés ou non, émanant des établissements d'enseignement et de recherche français ou étrangers, des laboratoires publics ou privés. 


\title{
Levels of angiogenic factors in patients with multiple myeloma correlate with treatment response
}

\author{
Ludek Pour • Hana Svachova • Zdenek Adam • Martina Almasi • Lucie Buresova • \\ Tomas Buchler • Lucie Kovarova • Pavel Nemec • Miroslav Penka • Jiri Vorlicek • \\ Roman Hajek
}

Received: 27 May 2009/Accepted: 10 September 2009/Published online: 26 September 2009

(C) Springer-Verlag 2009

\begin{abstract}
Angiogenesis plays a significant role in the pathogenesis of multiple myeloma (MM). We have measured concentrations of angiogenesis activators, including vascular endothelial growth factor (VEGF), basic fibroblast growth factor, and hepatocyte growth factor (HGF), and inhibitors, including endostatin, thrombospondin-1 (TSP1), and angiostatin in the peripheral and bone marrow blood of MM patients at diagnosis and after high-dose chemo-
\end{abstract}

This research was supported by grants MSMT LC 06027, MSM 0021622434, and IGA MZCR NR/9225

L. Pour $\cdot$ Z. Adam $\cdot$ M. Penka $\cdot$ J. Vorlicek $\cdot$ R. Hajek

Departement of Internal Medicine-Hematooncology,

University Hospital Brno, Masaryk University,

Brno, Czech Republic

L. Pour $\cdot$ H. Svachova $\cdot$ Z. Adam $\cdot$ M. Almasi $\cdot$ L. Kovarova

P. Nemec $\cdot$ M. Penka

Czech Myeloma Group, University Research Centre,

Brno, Czech Republic

L. Buresova $\cdot$ M. Penka

Institute of Biostatistics and Analyses at the Faculty of Medicine,

Faculty of Science of the Masaryk University,

Brno, Czech Republic

T. Buchler $\cdot$ M. Penka

Departement of Oncology, 1st Faculty of Medicine and Thomayer University Hospital,

Prague, Czech Republic

\section{Penka}

Departement of Clinical Hematology, University Hospital Brno, Brno, Czech Republic

\section{Pour $(\bowtie)$}

University Hospital Brno,

Jihlavská,

2062500 Brno, Czech Republic

e-mail: lpour@fnbrno.cz therapy. We have analyzed 96 patients with secretory MM. Serial measurements of angiogenesis factors/inhibitors were analyzed in the plasma by subgroups based on the best treatment response. Concentrations of angiogenic factors were determined in the peripheral blood and bone marrow plasma. There were significant decreases of VEGF and HGF levels and a significant increase in TSP-1 concentrations in the bone marrow plasma of patients who achieved complete or very good partial response in contrast to those who had partial or no response. VEGF and HGF levels decrease but those of TSP-1 increase after successful treatment for MM, indicating a reduction in the rate of angiogenesis.

Keywords Angiogenesis · Cytokines .

High-dose chemotherapy · Multiple myeloma .

Therapeutic response

\section{Introduction}

Multiple myeloma (MM) is characterized by proliferation of malignant plasma cells that accumulate in the bone marrow and often produce a monoclonal immunoglobulin [1]. MM was the first hematological malignancy in which increased angiogenesis rate was detected [2,3]. Angiogenesis activators thought to play a role in MM pathogenesis include vascular endothelial growth factor (VEGF), basic fibroblast growth factor (bFGF), and hepatocyte growth factor (HGF) [3-5]. They have been shown to stimulate the proliferation of malignant plasma cells as well as nonmalignant stromal cells. Plasma concentrations of these cytokines correlate with the Durie and Salmon stage [611], but the results of studies published to date are not conclusive as to their relative importance in pathogenesis and prognosis of MM [12]. There is little information on 
the role of angiogenesis inhibitors such as angiostatin, endostatin, thrombospondin-1 (TSP-1), or platelet factor 4 in MM [13]. So far, only one report has been published that showed increased levels of endostatin in a small cohort of MM patients [14]. It has also been reported that angiostatin gives a reduction in HGF levels, inhibits neovascularization, and slows tumor growth in an animal model of plasma cell malignancy [15].

The aim of this study was to measure the concentrations of selected angiogenesis factors/inhibitors including VEGF, bFGF, HGF, endostatin, TSP-1, and angiostatin in the platelet-poor bone marrow plasma (BMP) and platelet-poor peripheral blood plasma (PBP) of MM patients at diagnosis and after high-dose chemotherapy. The working hypothesis was that angiogenesis activators decrease, and conversely, inhibitors increase after successful therapy, reflecting a decreased rate of angiogenesis in responding patients. There is a clear evidence that the resistance to high-dose chemotherapy is also associated with a poor prognosis [16].

\section{Patients and methods}

\section{Patients}

We have analyzed 96 patients with secretory MM enrolled in the randomized CMG 2002 clinical trial [17]. The study treatment consisted of four cycles of induction chemotherapy with vincristin $(0.5 \mathrm{mg}$ i.v., day $1-4)$, doxorubicin $\left(9.0 \mathrm{mg} / \mathrm{m}^{2}\right.$, day $\left.1-4\right)$, and dexamethasone (40 $\mathrm{mg}$ p.o., day 1-4, 10-13, and 20-23; VAD). Stimulation chemotherapy with cyclophosphamide $2.5 \mathrm{~g} / \mathrm{m}^{2}$ followed by granulocyte colony-stimulating factor and myeloablative chemotherapy with melphalan $200 \mathrm{mg} / \mathrm{m}^{2}$. Baseline characteristics of the patients are shown in Table 1.

Treatment response

Serial measurements of angiogenesis activators/inhibitors were analyzed by subgroups based on the best treatment

Table 1 Baseline characteristics of patients

\begin{tabular}{llc}
\hline Number & & 96 \\
Mean age (range; years) & & 55.1 (28-72) \\
Males/females & & $51 / 45$ \\
Durie-Salmon stage & IA & 9 \\
& IB & 1 \\
& IIA & 13 \\
& IIIA & 56 \\
& IIIB & 14 \\
& Not known & 2 \\
\hline
\end{tabular}

response. Very good partial response (VGPR) was defined as reduction of monoclonal (M)-component by at least $90 \%$ of initial values. In our analysis, this subgroup included patients with complete response, i.e., disappearance of the M-component on electrophoresis and immunofixation. Partial response (PR) was defined as decrease in M-component by $50 \%$ to $90 \%$ and insufficient response (IR) as decrease in M-component by less than $50 \%[18]$.

\section{Sample processing}

After giving written informed consent to the study, patients had bone marrow aspiration from either the sternum or iliac crest. Peripheral venous blood sample was taken on the same day. All samples were immediately mixed with EDTA and centrifuged at $3,800 \mathrm{rpm}$ for $15 \mathrm{~min}$ at room temperature. BMP was always prepared from the first milliliter of the aspirated bone marrow.

\section{Cytokine measurements}

Measurements were done using ELISA kits according to the manufacturers' instructions. The following ELISA kit were used: human VEGF (R\&D systems, Minneapolis, USA), human bFGF (R\&D systems, Minneapolis, USA), human HGF (R\&D systems, Minneapolis, USA), human TSP-1 (Chemicon, Millipore, Billerica, USA), human endostatin (Chemicon, Millipore, Billerica, USA), and human angiostatin (Ray Biotech, Norcross GA, USA). For each patient, levels of the angiogenesis activators/inhibitors were measured at diagnosis and at the time of maximum treatment response, i.e., 1 to 6 months after high-dose chemotherapy.

\section{Statistical analysis}

Repeated-measures analysis of variance method was used to compare the changes in angiogenesis activators/inhibitors before treatment and after high-dose chemotherapy in subgroups with different treatment responses. The level of statistical significance was set at $p=0.05$.

\section{Results}

Of the 96 patients, $72(75 \%)$ had evaluable paired PBP samples, and $81(84 \%)$ had evaluable paired BMP samples taken at diagnosis and 1 to 6 months after high-dose chemotherapy. Hemolysis was the most common reason for sample invalidation. Results of HGF, VEGF, and TSP-1 measurements are summarized in Table 2. The decrease of VEGF levels in PBP of complete 
Table 2 HGF, VEGF, and TSP-1 levels in bone marrow plasma in multiple myeloma patients at diagnosis (timepoint A) and after high-dose chemotherapy (timepoint B)

\begin{tabular}{|c|c|c|c|c|c|c|}
\hline \multirow{3}{*}{$\begin{array}{l}\text { Sample } \\
\text { Response } \\
\text { Timepoint }\end{array}$} & \multicolumn{6}{|c|}{ Bone marrow plasma } \\
\hline & \multicolumn{2}{|l|}{ VGPR $n=38$} & \multicolumn{2}{|l|}{ PR $n=28$} & \multicolumn{2}{|l|}{ IR $n=13$} \\
\hline & A & $\mathrm{B}$ & A & $\mathrm{B}$ & A & $\mathrm{B}$ \\
\hline $\begin{array}{l}\text { VEGF } \\
\text { median } \\
\text { (range) } \\
\text { pg/ml }\end{array}$ & $\begin{array}{l}58(40-707) \\
p=0.005\end{array}$ & $29(19-102)$ & $\begin{array}{l}40(31-114) \\
p=0.281\end{array}$ & $47(13-169)$ & $\begin{array}{l}120(63-247) \\
p=0.082\end{array}$ & $83(17-91)$ \\
\hline $\begin{array}{l}\text { HGF } \\
\text { median } \\
\text { (range) } \\
\text { pg/ml }\end{array}$ & $\begin{array}{l}886(828-2,111) \\
p=0.041\end{array}$ & $782(707-1,641)$ & $\begin{array}{l}1,165(1,140-2,656) \\
p=0.244\end{array}$ & $987(903-2,432)$ & $\begin{array}{l}1,760(1,182-4,210) \\
p=0.315\end{array}$ & $2,090(1,199-4,865)$ \\
\hline $\begin{array}{l}\text { TSP-1 } \\
\text { median } \\
\text { (range) } \\
\mathrm{pg} / \mathrm{ml}\end{array}$ & $\begin{array}{l}351(337-917) \\
p=0.048\end{array}$ & $511(479-1,124)$ & $\begin{array}{l}303(279-705) \\
p=0.065\end{array}$ & $466(354-1,210)$ & $\begin{array}{l}246(167-798) \\
p=0.893\end{array}$ & $329(244-1,345)$ \\
\hline
\end{tabular}

$V G P R$ very good partial response, $P R$ partial response, $I R$ insufficient response, $V E G F$ vascular endothelium growth factor, $H G F$ hepatocyte growth factor, TSP-1 thrombospondin-1

response (CR) + VGPR patients was statistically significant $(p=0.016)$. There was also a statistically significant reduction of both HGF and VEGF concentrations in BMP after treatment in the CR+VGPR subgroup ( $p=$ 0.041 and $p=0.005$, respectively; Table 3 ). In contrast, there was no significant change in the levels of HGF or VEGF in patients who had PR or IR.

The patients who achieved CR or VGPR had a significant increase in the levels of TSP-1 in BMP after treatment ( $p=0.048$; Table 3 ). There was no change in TSP1 concentration in the subgroups with PR or IR. Changes in TSP-1 concentration in PBP were not statistically significant for any subgroup (Table 2).

No statistically significant differences between bFGF, endostatin, or angiostatin concentrations at diagnosis and after treatment in any of the patients' subgroups for PBP or BMP were observed (data not shown).

\section{Discussion}

Measurement of angiogenesis factors in the peripheral blood or in the bone marrow is a relatively simple and reproducible way for monitoring angiogenesis in hematological malignancies, including MM [4, 6, 10, 19, 20]. We have undertaken serial measurements of selected angiogenesis activators and inhibitors in MM patients. In accordance with published data, HGF and VEGF were the two angiogenesis activators that significantly responded to successful treatment $[8,19]$. There are contradictory reports

Table 3 HGF, VEGF, and TSP-1 levels in peripheral blood plasma in multiple myeloma patients at diagnosis (timepoint A) and after high-dose chemotherapy (timepoint B)

\begin{tabular}{|c|c|c|c|c|c|c|}
\hline \multirow{3}{*}{$\begin{array}{l}\text { Sample } \\
\text { Response } \\
\text { Timepoint }\end{array}$} & \multicolumn{6}{|c|}{ Peripheral blood plasma } \\
\hline & \multicolumn{2}{|l|}{ VGPR $n=33$} & \multicolumn{2}{|l|}{ PR $n=28$} & \multicolumn{2}{|l|}{ IR $n=11$} \\
\hline & A & $\mathrm{B}$ & $\mathrm{A}$ & $\mathrm{B}$ & $\mathrm{A}$ & $\mathrm{B}$ \\
\hline $\begin{array}{l}\text { VEGF median (range) } \\
\text { pg/ml }\end{array}$ & $\begin{array}{l}71(61-188) \\
p=0.016\end{array}$ & $22(20-91)$ & $\begin{array}{l}77(64-161) \\
p=0.079\end{array}$ & $34(21-96)$ & $\begin{array}{l}83(35-313) \\
p=0.315\end{array}$ & $103(13-575)$ \\
\hline $\begin{array}{l}\text { HGF median (range) } \\
\text { pg/ml }\end{array}$ & $\begin{array}{l}472(417-823) \\
p=0.014\end{array}$ & $398(354-475)$ & $\begin{array}{l}623(493-991) \\
p=0.07\end{array}$ & $526(303-1,230)$ & $\begin{array}{l}1,230(495-3,430) \\
p=0.121\end{array}$ & $1,036(321-32,228)$ \\
\hline $\begin{array}{l}\text { TSP-1 median (range) } \\
\text { pg/ml }\end{array}$ & $\begin{array}{l}464(385-826) \\
p=0.955\end{array}$ & $599(425-868)$ & $\begin{array}{l}378(328-642) \\
p=0.893\end{array}$ & $323(297-651)$ & $\begin{array}{l}568(411-860) \\
p=0.192\end{array}$ & $470(379-523)$ \\
\hline
\end{tabular}

$V G P R$ very good partial response, $P R$ partial response, $I R$ insufficient response, $V E G F$ vascular endothelium growth factor, $H G F$ hepatocyte growth factor, TSP-1 thrombospondin-1 
on the correlation between VEGF level and prognosis. Mileskhin et al. reported that high levels of VEGF were associated with response rate in patients treated with thalidomide [21]. On the other hand, Cibeira and collaborators have not confirmed any correlation between response rate and VEGF level [22]. We are the first to report that the angiogenesis inhibitor TSP-1 increases in patients who achieve CR or VGPR after first-line treatment for MM [23]. In MM, VEGF is produced by malignant plasma cells and stimulates the proliferation of endothelial cells. At the same time, endothelial cells in the tumor microenvironment also produce VEGF that acts in an autocrine and paracrine way on both endothelial and MM cells. Thus, there is a reciprocal stimulation between endothelial cells and malignant plasmocytes [24].

Concentrations of HGF are increased in MM patients as compared to healthy controls [8]. HGF promotes the adhesion of malignant plasma cells to fibronectin, a process which leads to the acquisition of resistance to cytostatic agents by MM cells and their enhanced survival [25]. HGF inhibits the proliferation of osteoblasts, and recent reports underline its importance in MM bone disease. HGF is also critical for increased bone marrow angiogenesis which is a key mechanism in the pathogenesis of MM [3, 4]. According to the results of our study as well as other reports, HGF is the single most useful angiogenesis activator for angiogenesis monitoring because its levels decrease in the peripheral blood as well as in bone marrow after successful treatment.

TSP-1 is an extracellular matrix protein produced by endothelial cells, fibroblasts, macrophages, monocytes, and some tumor cells [26]. There is an evidence for its inhibitory effect on endothelial cells through the induction of apoptosis, blocking of chemotaxis, and inhibition of new vessel formation [27]. Some preclinical data suggest that TSP-1 may have antineoplastic activity [13]. Our results showing an increase in the concentration of TSP-1 in the bone marrow of $\mathrm{MM}$ patients with good response to treatment may indicate that TSP-1 has a role in the pathogenesis of MM. In our hands, there was a wide variation in the levels of TSP-1 in the peripheral blood between individual patients probably caused by the release of the cytokine from activated platelets and endothelial cells in the peripheral vasculature. It has been proposed that the type of endothelium which is present in the tumor microenvironment produces less TSP-1 that the endothelium of normal capillaries, thus leading to disinhibition of tumor-associated angiogenesis [28].

It is more reliable to measure the concentrations of angiogenesis factors in the plasma rather than in the serum because platelets contain significant concentrations of these cytokines, releasing them upon coagulum formation during the preparation of serum [6]. Our previous data show the importance of analyzing the first milliliter of aspirated bone marrow because peripheral blood admixture may result in artifactual readings [29]. It is possible that discordant results published recently on the correlation between prognosis and angiogenesis-related cytokine levels are due to this methodological issue. We have also found that pretreatment concentrations of HGF and TSP-1 are predictive factors for treatment response. Patients with low angiogenesis rate as determined by HGF and TSP-1 concentrations were more likely to achieve complete or very good partial response after high-dose chemotherapy and probably had better prognosis than others [23].

In conclusion, the decreases in VEGF and HGF concentrations and the increase in TSP-1 concentration in patients with $\mathrm{CR}$ or VGPR indicate that the rate of angiogenesis is decreased after successful treatment for MM. We have shown in a large patient cohort that VEGF and HGF are the key angiogenesis activators, and TSP-1 is the most important angiogenesis inhibitor in MM.

\section{References}

1. Adam Z, Hajek R, Mayer J et al (1999) Multiple myeloma and other monoclonal gammapathies. Masaryk university, Brno 325

2. Vacca A, Ribatti D (1994) Bone marrow angiogenesis and progression in multiple myeloma. Br J Haematol 87(3):503-508

3. Vacca A, Ribatti D (2006) Bone marrow angiogenesis in multiple myeloma. Leukemia 20(2):193-199

4. Rajkumar SV, Leong T, Roche PC et al (2000) Prognostic value of bone marrow angiogenesis in multiple myeloma. Clin Cancer Res (United States) 6(8):3111-3116

5. Orpana A (2002 Feb) Angiogenic and lymphangiogenic molecules in hematological malignancies. Leuk Lymphoma 43(2):219 224

6. Neben K, Moehler T, Egerer G (2001) High plasma basic fibroblast growth factor concentration is associated with response to thalidomide in progressive multiple myeloma. Clin Cancer Res 7(9):2675-2681

7. Ščudla V et al (2006) Comparison of serum levels of selected biological parameters in monoclonal gammopathy of undetermined significance and multiple myeloma. Vnitr Lek 52(3):232240 Czech

8. Iwasaki T (2002) Predicting treatment responses and disease progression in myeloma using serum vascular endothelial growth factor and hepatocyte Folkman, J.: role of angiogenesis in tumor growth and metastasis. Semin Oncol 20:15-18

9. Sezer O, Jakob C, Eucker J et al (2001) Serum levels of the angiogenic cytokines basic fibroblast growth factor (bFGF), vascular endothelial growth factor (VEGF) and hepatocyte growth factor (HGF) in multiple myeloma. Eur J Haematol 66(2):83-88

10. Sato $\mathrm{N}$ et al (2002 Apr) Elevated level of plasma basic fibroblast growth factor in multiple myeloma correlates with increased disease activity. Jpn J Cancer Res 93(4):459-466

11. Wrobel T, Mazur G, Surowiak P et al (2003) Increased expression of vascular endothelial growth factor in bone marrow of multiple myeloma patients. Eur J Intern Med 14(2):98-100

12. Standal T, Abildgaard N, Fagerli U, et al HGF inhibits BMPinduced osteoblastogenesis: possible implications for the bone disease of multiple myeloma. Blood 109:3024-3030 
13. Voest E, D'Amore P (2001) Tumor angiogenesis and microcirculation. Marcel Dekker AG, New York, p 623s

14. Urbanska-Rys J (2003) High serum level of endostatin in multiple myeloma at diagnosis but not in the plateau phase after treatment. Mediat Inflamm 12(4):229-235

15. Du W et al (2006) NK4, an antagonist of hepatocyte growth factor (HGF), inhibits growth of multiple myeloma cells in vivo; molecular targeting of angiogenic growth factor. Blood 19; (Epub ahead of print)

16. Attal M, Harousseau JL, Stoppa AM (1996) A prospective, randomized trial of autologous bone marrow transplantation and chemotherapy in multiple myeloma. Intergroupe Français du Myélome. N Engl J Med 335(2):91-97

17. Hajek R, Spicka I, Scudla V et al (2007) Consolidation therapy based on conventional chemotherapy and corticoids do not provide therapeutic advantage for newly diagnosed patients after autologous transplantation. Blood 110:531

18. Durie BG, Harousseau JL, Miguel J et al (2006) International myeloma working group: international uniform response criteria for multiple myeloma. Leukemia 20(9):1467-1473

19. Alexandrakis MG, Passam FH, Sfiridaki A et al (2003) Elevated serum concentration of hepatocyte growth factor in patients with multiple myeloma: correlation with markers of disease activity. Am J Hematol (United States) 72(4):229-233

20. Smolej L, Andrys C, Belada D, Pour L, Zak P, Krejsek J, Novosad J, Hrudkova M, Siroky O, Voglova J, Maly J (2006) Plasma soluble endoglin (sCD105) concentrations in patients with lymphoid malignancies - a pilot study. Br J Haem 133(Suppl.1):104 abstract 269
21. Mileshkin L, Honemann D, Gambell P et al (2007) Haematologica 92:1075-1082

22. Cibeira MT, Rozman M, Segarra M et al (2008 Mar) Bone marrow angiogenesis and angiogenic factors in multiple myeloma treated with novel agents. Cytokine 41(3):244-253

23. Pour L, Svachova H, Adam Z, et al (in press) Pretreatment hepatocyte growth factor and thrombospondin-1 levels predict response to high-dose chemotherapy for multiple myeloma. Neoplasma

24. Vacca A, Ria R, Ribatti D et al (2003) A paracrine loop in the vascular endothelial growth factor pathway triggers tumor angiogenesis and growth in multiple myeloma. Haematologica (Italy) 88(2):176-185

25. Holt RU (2005) Human myeloma cells adhere to fibronectin in response to hepatocyte growth factor. Haematologica 90(4):479-488

26. Kazerounian K, Yee O, Lawler J (2008) Thrombospondins: from structure to therapeutics. Cell Mol Life Sci 65(5):700-712

27. Oganesian A, Armstrong LC, Migliorini MM (2008) Thrombospondins use the VLDL receptor and a nonapoptotic pathway to inhibit cell division in microvascular endothelial cells. Mol Biol Cell 19(2):563-571

28. Kalas W, Rak J (2005) Oncogenes and Angiogenesis: downregulation of trombospondin-1 in normal fibroblasts exposed to factors from cancer cells harboring mutant ras. Cancer Res 65 (19):8878-8886

29. Pour L, Kovarova L, Büchler T, Penka M, Vorlicek J, Hajek R (2009) Evaluation of hepatocyte growth factor and endostatin in the bone marrow of patients with multiple myeloma and the effect of peripheral blood admixture. Scripta medica 82:123-126 